New regulations and syllabuses for the graduateship examination, which will be in two parts, are to come into operation in 1962 . There were 820 candidates from 46 technical colleges for the Ordinary National Certificate in applied physics and 296 from 23 colleges for the Higher Certificate.

A new edition of the booklet "The Scientific Education of Physicists", which gives guidance on training and a summary of information about the physies departments of all universities and recognized technical colleges in Great Britain, was published during the year. A symposium on "Current Developments in the Production of High Vacua" was held in London on April 17, and a two-day conference on "Some Aspects of Magnetism" in the University of Sheffield during September 22-24. Summarized accounts of the proceedings of the symposium and of the conference have been published in the British Journal of Applied Physics. Books published for the Institute included reprints of the first five monographs in the "Monographs for Students" series, and a new volume, "Mechanical Design of Laboratory Apparatus", by H. J. J. Braddick ; "The Design of Physics Research Laboratories", the proceedings of a symposium arranged by the London and Home Counties Branch of the Institute; and a second edition of "Physics as a Career".

Details are given in the annual report of the amount of material submitted and published during the year in the Institute's two monthly journals, the British Journal of Applied Physics and the Journal of Scientific Instruments. The Journals Advisory Committee at its meeting, held during May, agreed that the scope of the British Journal of Applied Physics should not be limited despite the appearance of several new journals devoted to particular branches of applied physics. The circulation of the Journal continued to increase, but that of the Journal of Scientific Instruments showed a slight decrease for the first time for many years. The page size of the Bulletin was increased to conform with that of the two Journals, and the 324 pages of text, which contained about 22 per cent more material than the 336 pages of the 1958 volume, included twenty-five articles and 114 book reviews, in addition to Institute news.

The activities of the Australian, Malayan and the nine Great Britain branches, together with those of the specialist groups of the Institute, are outlined separately in the report. Two conferences were held by the Australian branch in Melbourne, the second "Conference on Contemporary Optics" during February 25-27, and the "Solid State Physics Conference" during August 17-21. A new division was formed in the Australian Capital Territory. The Applied Spectroscopy Group held an all-day symposium on "Reviews of Recent Developments in Spectroscopy" in May; the Education Group an Easter conference on the teaching of science to children up to the age of fifteen; the Electronics Group a two-day meeting in October on the subject of noise in electronic devices; and the Non-destructive Testing (Yroup the first joint conference with the Société Française de Métallurgie in Paris. The Stress Analysis Group undertook a new venture in April when it arranged a three-day international conference on stress analysis in Dolft, Holland. Fifty-one papers covering a wide range of topics were presented, and a selection of the papers is to be published in book form.

The annual dinner of the Institute was held on May 5, at the Park Lane Hotel, London, when 265 members and guests were present. The speakers were the president, Sir George Thomson, Sir Keith Murray, Sir Harry Melville and Mr. O. W. Humphreys. The alterations to the Institute's House, which had to be postponed for reasons of economy, were completed during 1959, and the senior staff dining room which had been used temporarily as an office was converted into a committee/dining room. The furnishings and décor were provided for by friends of the Institute and from the bequest of Mrs. W. Phillips. The Institute's accounts show a substantial increase in members' fees and on the publication business. $£ 3.450$ was transferred from the Institute's accounts to the Endowment Trust Fund account, but this was only just sufficient to cover the cost of the scientific and educational activities carried out by the Fund for the Institute. The Benevolent Fund continues to be well supported by members, and a further donation of $£ \mathrm{~A} .200$ received from the Australian Branch's Special Fund and an additional payment of $£ 258$ in respect of tax recovered on payments made by the Trust set up under the will of the late Mrs. W. Phillips were very welcome. During the year $£ 936$ was paid out in assistance to ten cases.

\title{
FERAL MUNTJAC DEER (MUNTIACUS SPP.) IN THE WEST MIDLANDS
}

\footnotetext{
$\mathrm{T}$ WO species of muntjac deer, the Chinese (Muntiacus reevesi) and the Indian (M. muntjac), were introduced into England at Woburn Park, Bedfordshire, about the beginning of this century. Later they were kept at Whipsnade and at least two private zoos (Crowland Abbey, near Wellingborough, and at Broxbourne, Herts). During the past half-century, muntjac have been reported in Bedfordshire, Northants, Warwickshire, Bucks, Herts, Berks, Cambridgeshire, Huntingdonshire, Essex, Leicestershire, Middlesex, Norfolk, Oxon., Staffordshire and Suffolk. Only in the last five counties can it be stated as certain that the deer are established as a regularly breeding species at the present time.
}

The successful colonization by the muntjac of a wide area of Britain has taken place very largely without the knowledge of its human inhabitants. T. J. Pickvance and J. S. R. Chard have prepared an article directing the attention of naturalists and others to the presence of this small deer and indicating some of the problems involved in recording the distribution and habits of the muntjac (Proceedings of the Birmingham Natural History and Philosophical Society, 19 , Part $1 ; 1960$ ).

The muntjac is unlikely to become the object of measures of extermination. Unlike the larger species of deer, it does no harm to trees, and from places where it sometimes becomes a nuisance, such as market 
gardens and allotments, it can be excluded by wire netting. Control will not prove difficult as it is easily caught, and, being a creature of habit in its movements, is not difficult to shoot. Its small size and retiring habits aid its unobtrusive spread. Thus, an increasing number of naturalists will be able to study this species which has an interesting form of territorial behaviour.
The main part of the article deals with records of the colonization by the muntjac of Warwickshire. These are typical of those gathered during surveys made with the view of determining not only the present distribution of the animal but also the rate and direction of colonization and the past history of the movements which have taken place.

\title{
NOMENCLATURE OF THE NICOTINAMIDE NUCLEOTIDE COENZYMES
}

\author{
By DR. MALCOLM DIXON, F.R.S. \\ Department of Biochemistry, University of Cambridge
}

\begin{abstract}
$\mathrm{T}$ HE nomenclature of the nicotinamide nucleotide coenzymes has been a subject of long-standing disagreement, and unanimity has not yet been reached. Several different systems are in use to varying extents.

Included with other subjects in the terms of reference of the Enzyme Commission of the International Union of Biochemistry ${ }^{1}$ is the nomenclature of enzymes and of coenzymes, and during the past three years the Commission has been giving careful and detailed consideration to the question of coenzyme nomenclature in an effort to reach a generally acceptable solution. The question has also been considered by the Biological Chemistry Nomenclature Commission of the International Union of Pure and Applied Chemistry. A summary of the points involved and the reasons for the recommendations of the Commissions may be of interest.
\end{abstract}

\section{Present Position}

The situation that has to be faced is that, except perhaps in the United States, there is no unanimity about the naming of the two coenzymes. Four different systems are in use, although to very different extents, and the special difficulty of the position arises from the fact that the system that is most used is that which has the strongest objections from the chemical point of view. The four systems are: (a) cozymase and phospho-cozymase ; (b) codehydrogenase I and codehydrogenase II (or codehydrase I and codehydrase II by some Continental writers) ; (c) coenzyme I and coenzyme II (abbreviated to CoI and $\mathrm{CoII}) ;(d)$ diphosphopyridine nucleotide (DPN) and triphosphopyridine nucleotide (TPN). The first system is probably the least, and the fourth the most, used at the present time. None of these systems is satisfactory, the first three because they are uninformative, the last because it is incorrect, as a number of reviewers have pointed out ${ }^{2-5}$.

There is rather more consistency among the journals than there is among authors of books and reviews. The Journal of Biological Chemistry, which had previously used both cozymase and coenzyme I, first used diphosphopyridine nucleotide in about 1940 ; and it has continued to do so, along with cozymase and coenzyme I, until about 1950 , and as the sole form after that date. The Biochemical Journal used cozymase and coenzyme I, and did not permit diphosphopyridine nucleotide, until as recently as 1953 , but since then has used the last name almost entirely. The index of Chemical Abstracts, however, still uses codehydrogenase I rather than DPN.

\section{Di- and Tri-phosphopyridine Nucleotide}

There would be no objection whatever to the use of the names diphosphopyridine nucleotide and triphosphopyridine nucleotide if they did not indicate chemical structures, but the main objection is, in brief, that not only do they fail to give the structure of the coenzymes properly but also that they are the chemical names of other compounds. It is somewhat like using the name 'methyl acetate' for pyruvate; the name indicates a structure, but it is the wrong structure.

The names are derived from, though not the same as, names introduced by Warburg' ${ }^{6}$ in 1936 as convenient descriptions. The term 'pyridine nucleotide' was used, quite legitimately, to distinguish this class of compounds from purine nucleotides such as the adenine nucleotides. To distinguish the coenzymes from each other they were described as 'the diphospho-' and 'the triphospho-pyridine-nucleotide', at first with the definite article, although this was almost immediately dropped and the terms thereafter used as names in the German forms 'Diphospho-Pyridin. nucleotid' and 'Triphospho-Pyridinnucleotid'.

'Diphospho $\therefore$ '. In 1939, F. G. Fischer', in his review on the subject, pointed out that these names, though concise, were incorrect. According to chemical terminology, 'phospho- $X$ ' denotes $X$ combined with an additional phosphate group; but the word 'nucleotide' already includes a phosphate group, thus a 'diphospho-(di)nucleotide' would contain four phosphate groups, and not two as does the coenzyme. Fischer suggested that, especially in relation to the accepted names of the analogous flavin nucleotides, the names 'Pyridine-Adenine-Dinucleotide' and 'Phospho-Pyridine-Adenine-Dinucleotide' would be clearer. They would have the advantage of showing that the compounds are dinucleotides containing adenine, which was not indicated by the earlier names. Probably because of the outbreak of war in the same year, these suggestions did not receive the attention they deserved.

'Triphospho.'. It was at first believed that the three phosphate groups of triphosphopyridine nucleotide were joined in line, as in adenosine triphosphate, so that the relationship between the two coenzymes would be analogous to that between adenosine diphosphate and adenosine triphosphate. When the true structure of triphosphopyridine nucleotide was determined by 1950 by Kornberg and Pricer ${ }^{7}$, it was found to be a monophospho-dinucleotide, so that the prefix 'triphospho-' became less appropriate.

'Diphosphopyridine-'. Perhaps the most serious objection arose when the names became anglicized, 